\title{
Environmental technology education in Portugal: analysis and perspectives
}

\author{
A.G. Brito, ${ }^{*}$ L.F. Melo* and F. Santana** \\ *University of Minho, IBOF, Department of Biological Engineering, 4700 Braga, Portugal \\ ${ }^{\star *}$ New University of Lisbon, Department of Environmental Sciences and Engineering, \\ 2825 Monte da Caparica, Portugal
}

\begin{abstract}
The scope of the present communication is the current status of environmental engineering in Portugal. The different approaches concerning the environmental engineering courses available at undergraduate levels as well as some post-graduation studies are described. Furthermore, an analysis based on strengths, weakness, opportunities and trend issues regarding the environmental engineering profession in Portugal is presented.
\end{abstract}

Keywords Environmental engineering; education; curriculum; Portugal

\section{Introduction}

The scope of environmental engineering (EE) is defined by the Portuguese Association of Environmental Engineers (APEA) as follows: "Environmental Engineering is a branch of Engineering that studies the environmental problems in their technological, ecological, social and economical dimensions in order to promote a sustainable development". This broad approach is similar to the one used in the United States, as presented by Bishop (2000). The environmental engineer is prepared to design a solution for an environmental problem. Thus, typical areas in which the environmental engineer is concerned are water, soil and air pollution. Wastes and resources management (e.g., environmental impact assessment, geographical information systems, risk assessment, regional planning) are also within their scope. New tasks are coming from the widespread setting of international certification standards, like ISO 14000 and EMAS (EC). As a result of the multi-disciplinary academic curriculum, the environmental engineer has an integrated vision of the problems raised by human society activities. This tool enables him to cooperate and to communicate with other technicians, as well as to seek and promote public participation whenever necessary. Of course, environmental education and scientific research are fundamental issues that the environmental engineering community shares with other professionals.

In Portugal, environmental engineering education is provided through three different options, as follows:

1. 5 year undergraduate studies named "Environmental Engineering";

2. specialised final branch within an undergraduate study (e.g., civil, chemical and biological engineering); and

3. by having specialised lectures within an undergraduate curriculum (often as an optional discipline).

All these three different approaches have their merits, advantages and weaknesses. In that regard, a survey of environmental engineering education in Portugal is presented. Focal points and trends in the framework of the local situation are also discussed.

\section{Environmental engineering undergraduate studies}

The first undergraduate courses on Environmental Engineering in Portugal were started more than 20 years ago, in the academic year of $1977 / 78$. The initiative was promoted by the 
New University of Lisbon (Faculty of Sciences and Technology) and by the University of Aveiro. The studies last for five years, which is the Portuguese standard at university level, leading to the so-called "licentiateship". The curriculum encompassed the traditional engineering disciplines with an additional knowledge of environmental chemistry and biology. In 1987, the New University of Lisbon reorganised the Environmental Engineering studies into two branches called "Environment" and "Sanitary" respectively, the last one being more focused on wastewater systems. During the 1990s, most Portuguese universities also launched similar "licentiate" degrees and now there are already nine 5-year technological courses in Portugal with the denomination of "Environmental Engineering". It should be noted that this number does not account for other engineering studies that have the "environment" denomination attached to another name in their title. They are considered hybrid courses (option 2) in the present analysis and thus are presented in the next section. Two of the nine Environmental Engineering courses are lectured at private universities (22\%). Figure 1 clearly displays the increase of those courses, which has become stronger since 1993. As a consequence of such growth, the APEA recorded nearly 900 members in 1998 , considering graduates and students of environmental engineering. This is a very significant number, emblematic of the importance of this profession in Portugal.

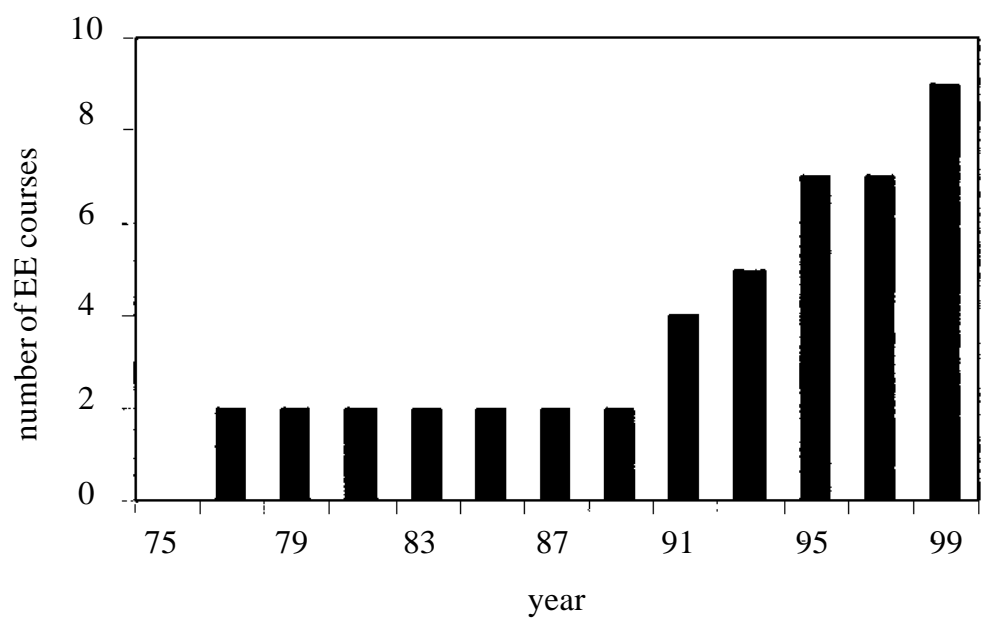

Figure 1 Number of Environmental Engineering undergraduate courses in Portugal

Until now, of the aforementioned courses only the New University of Lisbon and University of Aveiro studies received the accreditation of the Portuguese Institution of Engineers. This number should increase in the near future as the accreditation process continues.

According to the information provided by APEA (1998), environmental engineers have a heterogeneous distribution over the professional market. Figure 2 presents the available data on that question.

As can be seen, the main employment areas of environmental engineers are research and university education (29\%) and consulting firms (18\%). If all public administration jobs are aggregated, they will also represent an important fraction (28\%). This was expected on account of the known environmental management and legal compliance tasks that were (and still are) necessary in Portugal, mainly after the European Community membership. The industry representation was not much significant, only $6 \%$. Indeed, only very recently did Portuguese industry begin to implement pollution prevention measures and for this purpose consulting and commercial firms are first required (technicians working at equipment 


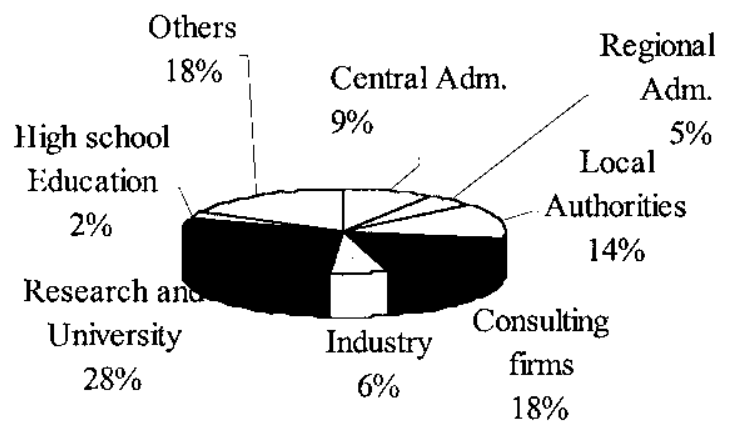

Figure 2 Employment distribution of EE (source: APEA, 1988)

suppliers are encompassed in "others"). On the other hand, such data may also suggest that the industry may be an interesting target for other environmental professionals.

\section{Environmental engineering education within other courses}

An important source of environmental education was always provided by Civil Engineering courses. Traditionally, civil engineering offers training in areas like water (including groundwater), wastewater and solid waste management, as part of the so-called sanitary engineering field. The studies of the Technical University of Lisbon are well known in this area. Nevertheless, the focus is mainly the urban community. Thus, in general, a certain lack of microbiological and biochemical background weakens their integration in the industrial field, particularly as regards the treatment of wastewater and gaseous emissions. On the contrary, the courses provided by some Chemical Engineering programmes are intended to fill this gap, providing some education on environmental technology. In general, these courses do not address areas such as water and sewerage systems, river basin management, solid wastes collection and transport.

Recently, hybrid types of undergraduate studies have begun to provide a sound industrial engineering knowledge in the first years and thereafter a more intensive training in environmental technology than formerly. The conceptual base relies on the fact that most Portuguese industries are of small-scale dimension and thus the technical staff are expected to perform activities related to in-plant process in complement to the environmental area. In the framework of this definition, the hybrid engineering courses have the word "Environment" or a related name attached to their denomination. An example of this type of educational offering is the Biological Engineering - Pollution Control option at the University of Minho, launched in 1991, which has the accreditation of the Portuguese Institution of Engineers. This 5 year course was structured in order to establish an interface between chemical engineering and biological sciences, especially microbiology and biochemistry. The environmental teaching starts at the beginning of the fourth year. The practical training is more relevant than that observed in other engineering courses, around $25 \%$ of the total number of classes being laboratory classes. An additional important point is that the last semester is undertaken in industry: a professor from the University and a technician from the industry both supervise this period of training. Figure 3 presents the current employment situation of the graduates. The data correspond to a survey that is still in progress and so it concerns approximately $70 \%$ of all graduates in Biological Engineering, Pollution Control branch, that is 76 individuals.

Figure 3 also indicates a heterogeneous distribution of those professionals. Comparing with the data shown in Figure 2 regarding the environmental engineers, a low number of 


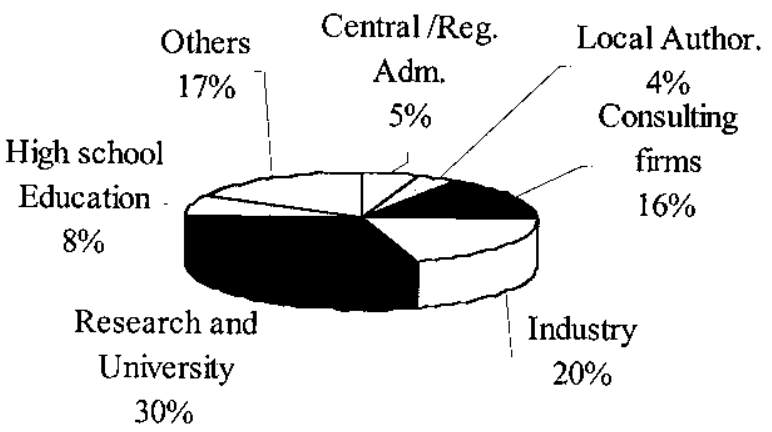

Figure 3 Employment distribution of Biological Engineering - Pollution Control graduates

biological engineers is found in state administration and a higher number in industry. The regional characteristics (Portugal is a centralised state in terms of public administration) prevent the linear conclusion that these graduates are not required by the administration. Moreover, the north of Portugal (where the University of Minho is located) is one of the most industrialised areas in Portugal so it will be easier for them to work in the industrial field. Anyhow, the data indicate a trend that cannot be ignored, which is in accordance with the initial expectations. It is very interesting to note that graduates also fulfil important research positions, in a similar way as environmental engineers of option 1 did (Figure 2). It is interesting to note that some other hybrid types of 5 year courses embrace a different background, emerging from the forest sciences and/or other natural products (e.g., paper, leather). This is the case of the Environmental and Natural Resources Engineering course, lectured at the University of Tras-os-Montes e Alto Douro.

Finally, the last aforementioned option regarding environmental engineering education (option 3) concerns the courses that incorporate just one environmentally oriented discipline, typically mostly related with the impact of the main scope of the course. This approach is, for instance, applied in the Textile Engineering and Mechanical Engineering studies at the University of Minho. It is expected that this training will provide the future engineers with a serious consciousness of the ecological impacts of their profession, educating them to minimise the potential problems already in the conceptual design phase of the process. If the problem is not solved there, the task will need the skills of the professionals with the environment background of type 1 and 2 .

\section{Master's courses and doctoral degree}

In Portugal, the Master's course comprises two main parts: one year of lectures and practical classes, followed by a twelve month supervised original research work, which is examined by a qualified jury. In 1998, advertising information regarding 26 Master's degree courses in areas related to environmental issues was available. It seems to be a large offering but it should be noted that only seven courses had an engineering approach (27\%). The majority were environmental science courses (e.g., ecology, coastal sciences, human ecology, regional planning) being mostly guided for scientific research or educational purposes. A few examples of the "engineering" courses were the Master's in Air Pollution (University of Aveiro), Sanitary Engineering (New University of Lisbon), and Environmental Engineering (University of Minho) and the ones related with agronomic studies.

Doctoral programmes are also available at Portuguese universities. A few examples: the New University of Lisbon offers a PhD named Environmental Engineering, already cover- 
ing a broad range of themes such as wastewater treatment, solid wastes, environmental impact assessment; the University of Aveiro is mostly focused on air pollution, but also wastewater treatment; the University of Minho offers a $\mathrm{PhD}$ degree in "Chemical and Biological Engineering" that encompasses environmental engineering studies. Other universities, such as the Technical University in Lisbon and the University of Porto also offer doctoral studies in environmental subjects.

\section{Environmental engineering in Portugal: a SWOT analysis}

The assessment of the environmental engineering status in Portugal is carried out using a type of SWOT (strengths, weaknesses, opportunities and threats) analysis, as follows.

\section{Strengths}

After twenty years of existence, environmental engineering courses are well perceived by Portuguese society and well known at different levels. Their professional scope is accepted, scientific work is substantial, educational activities are performed. In that sense, we may consider that the educational goal of the concerned universities was attained. Outside the academic field, the existence of some non-profit organisations was very important for such achievement. In the first place, the ecological associations that are politically active, receiving substantial media coverage should be mentioned (e.g., Quercus, LPN, Geota). Their work still is very important as a catalyst of public concern about environmental themes, which means that, sooner or later, the politicians' attention will be reached and thus public funds for rehabilitation/protection works will be available. The same goal applies to other scientific and technical organisations that exist in Portugal, mainly with a sanitary engineering scope (e.g., APRH-Water Resources Association, APESB-Sanitary Engineering Association), all sponsors of known international associations. Finally, it is interesting to observe that an association of environmental equipment suppliers, one of water distributors and even an environmental lawyers association (specialised courses on environmental law were given last year) are also active. All of them contributed through these years to sustain the environmental sciences and engineering in Portugal.

On the other hand, the existence of professional organisations was (is) also very important for the development and solidification of such a new profession in Portugal. In that regard, an important and valuable role was played by APEA, the Portuguese Association of Environmental Engineers. This association was founded in 1985 and carried out a continuous and decisive lobbying for EE promotion. Seminars, conferences, periodical news, jobs announcements and so on were provided since it was founded. The Portuguese Institution of Engineers (PIE) has been also a supporter of the environmental engineers. The environmental engineering graduates could choose between the civil and the chemical colleges when they came to affiliate. But finally, after the recommendations of a consulting committee, an Environmental Engineering college was created at the beginning of 1999. This decision clearly represented a major milestone.

\section{Opportunities}

According to Llera (1998), in order to reach the top ten ranking of dedicated environmental firms in Portugal, an annual turnover of only 1.3 millions of Euro (MEuro) was sufficient in 1995. However, in order to attain the same level only after three years (in 1998), a turnover of 7.9 MEuro was necessary. These data show how the market demand is rising fast. The private sector is offering more jobs: the 60 most important environmental companies had 1406 employees in 1996 but the number increased to 2176 in 1998, while the biggest public 
company in the water sector already employs 1380 staff. In 1996, the industrial and the public administration expenditure in environmental protection in Portugal amounted to 66 Euro/per person. Considering public investment, 1000 MEuro were spent in 1994/96, this amount being estimated to rise to 2425 MEuro in the 1997/99 period. Solid wastes, including the rehabilitation of disposal sites, was the major target. The last official information about private investment (industrial) concerns 1996 and indicates an expenditure of around 170 MEuro. This value was mainly applied in air pollution abatement by some major companies (refineries, paper) and so the idea that water pollution caused by industry may be 2 to 3 times higher than that represented by municipal facilities is still currently accepted in Portugal. Consequently, the environmental market of the industrial sector is still in its youth and will be a new sales target. Thus, the prospects for the coming years in terms of graduate employment are also favourable. Wastewater, industrial air pollution (in small industries), soil decontamination, hazardous wastes, environmental management systems seem to be among the new focal points for the coming years.

\section{Weaknesses}

Academic background at the undergraduate level must be attuned with society's needs. Thus, an important problem may arise in the case of some environmental engineering university studies with a program leading to a poor understanding of EE scope or being deficient in curriculum quality. This question cannot be neglected and must be handled by a continuous assessment, performed by the universities themselves and by outside educational agencies. Besides, an accreditation process by professional organisations should be mandatory for all EE courses and the existence of courses that fail to pass the process should be avoided. The Portuguese Institution of Engineers has a decisive role in order to guarantee the quality control of all engineering courses, including EE ones, as far as the accreditation granted by PIE is the most important factor for public acceptance of an engineering course.

A clear definition of areas of competence in environmental projects is also needed. Despite the fact that other professionals often participate in the design of environmental projects (e.g., civil, electrical, and mechanical works) only a member of the College of Environmental Engineering (which is not exclusive of environmental engineers graduates) should be allowed to be the lead individual responsible for environmental projects. Of course, well defined admission criteria for College membership have to be clearly stated if that is the case.

Finally, another problem remains with the fact that no operational channel exists for the exchange of educational material dedicated to environmental studies among university teachers. Besides, the communication between teachers of environmental sciences and engineering oriented disciplines is very thin and not structured. Both phenomena tend to isolate each teacher, restraining the up-to-date formation and the common definition of long-term goals. Moreover, international links with other teachers regarding environmental education themes (but not in research areas) are very few, owing to the lack of an appropriate international association.

\section{Trends and acknowledgements}

The employment market is the final arbiter of the educational approaches considered by the three types of educational options present in Portugal. Indeed, the question of which is the best environmental engineering approach is hard and probably difficult to forecast. Thus, market selection will provide appropriate answers to this question. Up to now, as previously described, the employment ratio has been highly positive for all academic approaches, sustaining the growth in environmental education in recent years. However, considering the 
large number of undergraduates that are now enrolled in universities (in options 1 and 2), the answer may be different in the near future. If that happens, only the best faculties will continue to do their work. Because of that, the quality of university teachers (not only curricula and academic facilities) will be important.

\section{Acknowledgements}

The authors are very grateful to Dr. J. Azeredo for providing the data about the professional situation of the Biological Engineering graduates.

\section{References}

APEA (1998). 98 Yearbook of environmental engineers. Eds. Associação Portuguesa dos Engenheiros do Ambiente, Lisboa, 1998.

Azeredo, J. (1999). "Biological engineers after graduation: a survey”. Personal Communication.

Bishop, P.L. (2000). Environmental engineering education in North America. Wat. Sci. Tech. 41(2), 9-16 (this issue).

Llera, G. (1999). Menor crescimento e mais especialização. In: Environment, Ed. Diário de Noticias, Lisboa. 